\title{
Coil or intrauterine device? Patient preferences for contraceptive terminology
}

\author{
Nicola Mullin, DFFP, MRCOG, Clinical Lecturer in Family Planning; Kathryn Mills, Fourth Year Medical Student; \\ Rosemary Kirkman, FRCOG, MFFP, Senior Lecturer in Family Planning and Well Woman Care, University of Manchester, \\ Manchester, UK
}

Correspondence: Dr N Mullin, The Palatine Centre, 63-65 Palatine Road, Manchester M20 3LJ, UK. Tel: +44 (0) 161434 3555.E-mail: nicola@nmullin.freeserve.co.uk

(Accepted 17 September 2003)

Journal of Family Planning and Reproductive Health Care 2004; 30(1): 46-48

\begin{abstract}
Objective. To discover what terminology women prefer to use when referring to contraceptive methods and to investigate the understanding of and ideas associated with contraceptive names.

Design. A self-administered questionnaire was answered by 191 new patients at family planning clinics (FPCS). Women were asked if they understood the terms used by the fpa (Family Planning Association), if they knew of any alternatives and, if so, which they preferred.

Setting. Selected FPCs across the city of Manchester.

Results. Patients preferred to use familiar terms, e.g. pill, mini-pill, coil and morning-after pill. There was no difference in preference when the results were compared by age or educational level. A greater proportion of nonCaucasians than Caucasians preferred the precise (fpa) terms. Although precise terms were not widely known or understood, when used they were associated with more information than were the familiar terms.

Conclusion. All FPC staff should evaluate the language used by individual patients and, where appropriate, introduce precise terminology to help patients to make informed, appropriate choices.

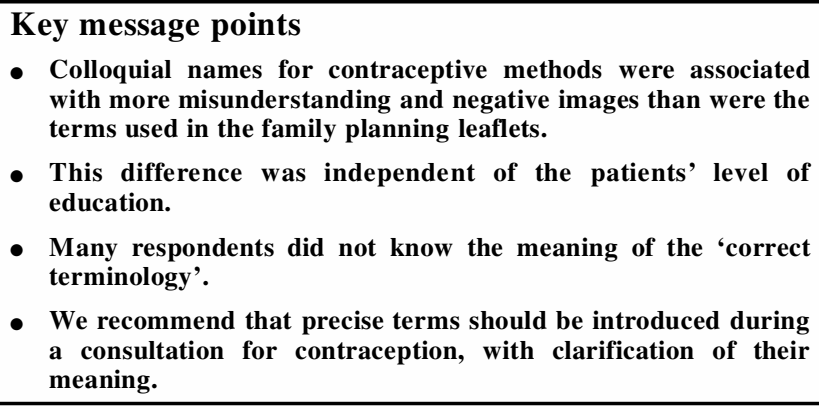

\section{Introduction}

The ideal clinical consultation has been widely written about, particularly the style, structure and content. ${ }^{1-5}$ In contraception and sexual health consultations, vocabulary and embarrassment may inhibit patient understanding. ${ }^{6}$ The need to choose words appropriate for the user is highlighted by the Plain English Campaign. ${ }^{7}$ There is an emphasis on avoiding jargon, which they define as language only understood by a particular group of people. Specialist language has developed to facilitate interaction between members of subgroups in society and serves an important purpose. However, medical jargon is often meaningless to patients and may result in confusion.

We noticed that patients were using different terminology for contraceptive methods than were clinic staff and were not always familiar with the correct terms as stated in fpa (Family Planning Association) leaflets.
Patients appeared to have strong negative and positive perceptions of individual methods. When a word is used, both parties may presume that they understand the term and are talking about the same thing, when in fact they are not and have interpreted the term differently, e.g. missed abortion, incompetent cervix and inadequate cervical smear test result. It is therefore important to clarify that terms are being used correctly.

It has been suggested that jargon may be used subconsciously as a control mechanism. , $^{2-10}$ When doctors focus on their own agenda (fact finding) they are in direct control. As the style of consultation becomes increasingly patient-centred, the doctor loses power and authority. Different groups in society have their own needs and preferences in medical consultations. One study ${ }^{11}$ highlighted the difficulties that non-professional Asian women have in accessing and using contraception including communication problems but also lack of preexisting knowledge and low levels of personal autonomy. It found that these women related to family planning terminology differently to clinic staff and did not understand some common words such as coil or cap. In a study from Leicester in Gujarati speakers ${ }^{12}$ when ad hoc interpreters are used, between $25 \%$ and $52 \%$ of words were translated incorrectly. Technical words were translated incorrectly more often than were simple words.

\section{Method}

During the period May-June 2002, a questionnaire was given to all new female patients attending five family planning clinics (FPCs) to find out their preferences for contraceptive terminology. FPCs with relatively high attendance figures were selected from across the city, from each of the three primary care trusts, to provide a good cross-section of population for age, educational level and ethnic groups. Only new patients to the FPC were included, to try to eliminate any influence from previous contact with family planning-trained staff. The questionnaire was selfadministered, with help from a companion if necessary, while patients waited to see the nurse or doctor, and placed anonymously in a box in the reception area.

A pilot study of 50 patients was carried out initially to identify any ambiguities with the questionnaire. Questions about eight of the most common contraceptive methods were included, namely the condom, combined oral contraceptive pill, progestogen-only pill, intrauterine device, diaphragm, contraceptive injection, implant and emergency contraception. Women were asked if they knew any alternative names for these methods and, if so, which name they preferred and why. A further question asked them to identify sources of information they used to find out about contraception.

In the pilot there were a variety of answers given for 
four terms in particular (i.e. combined oral contraceptive pill, progestogen-only pill, intrauterine device and emergency contraception) so we decided to concentrate on these methods. To determine whether blank answers were because the patients did not understand the question, or due to true indifference, an option to tick a box if not sure of the method was included in the final version. In order to discover if alternative names for the same contraception have different associations (either positive or negative), respondents were asked what two different terms for the same method made them think of. For this exercise we used coil compared to intrauterine device, and mini-pill compared to progestogen-only pill. Ethics approval for the study was received from the North Manchester Local Research Ethics Committee.

\section{Statistical analysis}

The results were collated in Excel and analysed using SPSS Version 9. Analysis was subdivided according to age, educational level and ethnic group. Categorical data were compared using a two-sided Fisher's exact test because of the small sample size. The standard significance level of 0.05 was used for all statistical comparisons.

\section{Results}

During the main study, 222 copies of the questionnaire were given out and 191 were completed giving a response rate of $86 \%$. The ages of the patients ranged from 15 to 51 years with $62 \%$ in the 20-29 years age range. Ten $(5 \%)$ people did not reply to this question. One-third (33\%) of the respondents indicated that they had received higher education, $11 \%$ had studied to A-level standard and $23 \%$ had received a basic level of education. The remaining $33 \%$ respondents did not answer or misunderstood this question. Those respondents that answered White British, White Other and Irish were classified as Caucasian. All other answers were counted as non-Caucasian. The ethnic mix of the sample was $75 \%$ Caucasian and $25 \%$ non-Caucasian. Nine $(4.7 \%)$ people did not answer this question.

\section{Understanding}

This question asked for alternative names for combined oral contraceptive pill, progestogen-only pill, emergency contraception and intrauterine device and which name, if any, was preferred (Figure 1). We found that $45 \%$ of respondents for progestogen-only pill and $45 \%$ for intrauterine device ticked the box indicating they were not sure what the method was. However, only $17 \%$ of respondents for combined contraceptive pill and $11 \%$ for emergency contraception were not sure of the method.

In addition, the answers were categorised as misunderstood if the patients had not ticked that they did not understand, but clearly gave an incorrect term such as 'cap'. It should be noted that for the progestogen-only pill this was difficult to determine as a large proportion gave the name 'pill' and are shown as 'Ambiguous' in Figure 1.

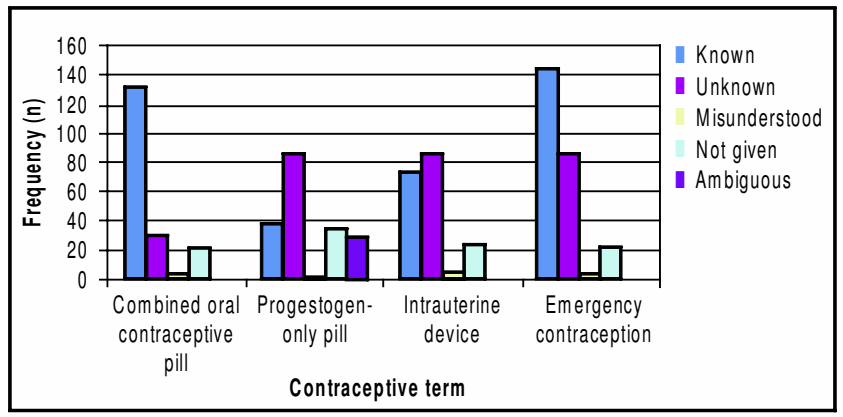

Figure 1 Summary of the understanding of the contraceptive terms given on the questionnaire

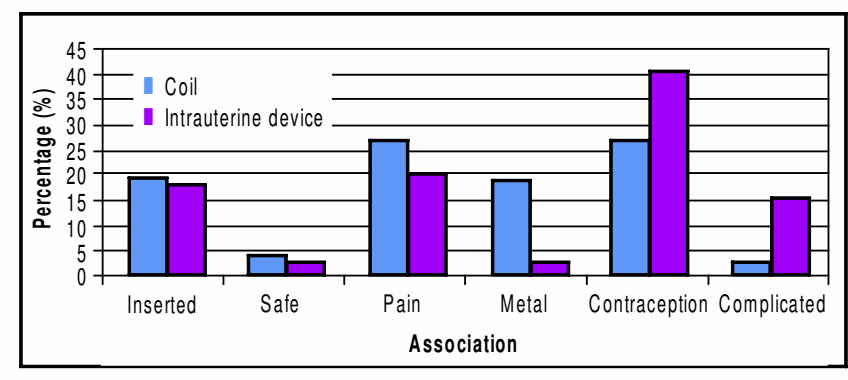

Figure 2 Comparison of the associations linked to the names coil and intrauterine device

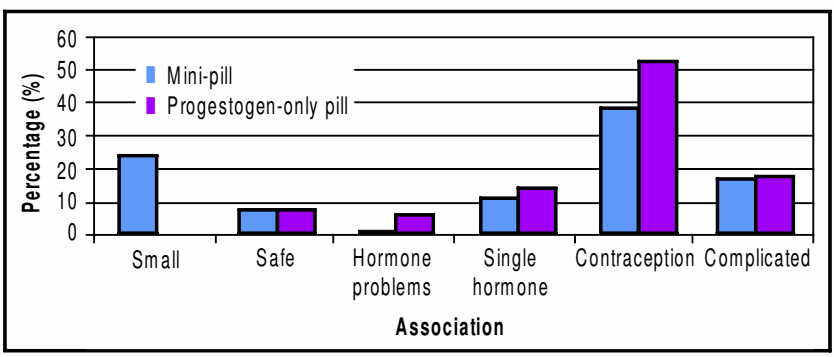

Figure 3 Comparison of the associations linked to the names mini-pill and progestogen-only pill

\section{Associations}

The four terms investigated for their associations were coil, intrauterine device, mini-pill and progestogen-only pill. In answer to the question 'What do the following words make you think of?' we found that the most common response was 'contraception' or words explaining how the method was used and who it was suitable for: coil 38/139 (27\%), intrauterine device 29/74 (39\%), mini-pill 38/99 (38\%) and progestogen-only pill $41 / 77$ (53\%). The number of respondents for each question varied.

Of the responses about the terms coil and intrauterine device, $38 / 139(27 \%)$ and 14/74 (19\%), respectively, associated them with pain and bleeding. For the coil 26/139 $(19 \%)$ of the comments were to do with its physical shape and composition, including 'metal', 'spring' and 'snake'. Only $2 / 74(3 \%)$ of the responses for the intrauterine device linked it to metal or wires. Equal proportions for the terms coil and IUD, 27/139 (19\%) and 13/74 (18\%), respectively, thought about it being inserted into the body (Figures 2 and 3 ).

Many people did not reply to these questions. The colloquial terms, coil 52/191 (27\%) and mini-pill 92/191 $(48 \%)$, were left blank by fewer people than the precise terms, intrauterine device $117 / 191(61 \%)$ and progestogenonly pill $114 / 191(60 \%)$.

\section{Terminology}

In response to the question 'Which name do you prefer?' the majority of respondents preferred to use the colloquial term for all four of the contraceptive methods on the questionnaire and several alternative names were given. These were grouped together into those recommended by

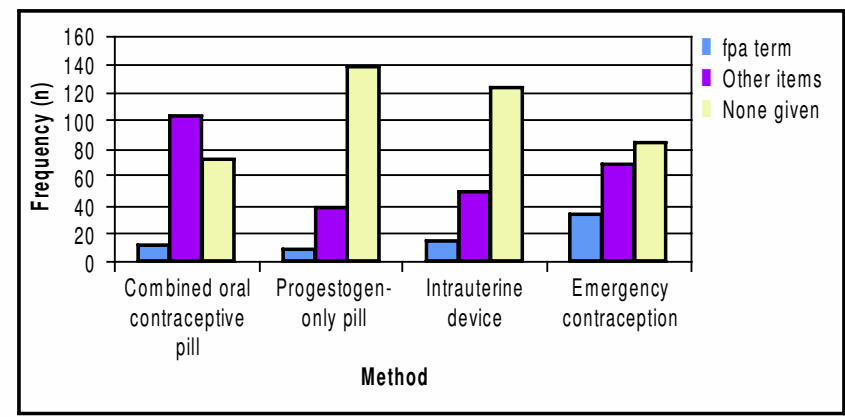

Figure 4 Summary of preferred terms for the various contraceptive methods 
Table 1 Information sources that patients preferred to use to find out about contraception

\begin{tabular}{ll}
\hline Information source & Responses (n) \\
\hline Chatting with friends or relatives & 123 \\
Leaflet & 105 \\
Explanation/demonstration by nurse & 101 \\
Magazine & 84 \\
Explanation/demonstration by doctor & 61 \\
TV & 38 \\
Internet & 18 \\
Telephone helplines & 11 \\
Other (job, school sex education) & 4 \\
\hline
\end{tabular}

the fpa, others (colloquial names) and no preference (Figure 4).

The frequencies of preferred terms for the combined oral contraceptive pill were: pill 90/191 (47\%), no preference 74/191 (39\%), contraceptive pill 11/191 (6\%), combined oral contraceptive pill 8/191 (4\%), combined pill 4/191 (2\%), brand names and mini-pill both 2/191 (1\%).

The frequencies of preferred terms for the progestogenonly pill were: no preference $140 / 191$ (73\%), pill 26/191 (14\%), mini-pill 15/191 (8\%) and progestogen-only pill 10/191 (5\%).

The frequencies of the preferred terms for the intrauterine device were: no preference 125/191 (65\%), coil 48/191 (25\%), intrauterine device 15/191 (8\%) and loop, condom and 'sterilet' each $1 / 191(0.52 \%)$.

The preferred terms for emergency contraception were: no preference 85/191 (45\%), morning-after pill 69/191 (36\%), emergency contraception 35/191 (18\%), loop, condom and 'sterilet' each $1 / 191(0.52 \%)$.

There was no statistically significant difference in the preference when the results were compared for age or level of education received. However, there was a significant difference according to ethnic group for the terms used to describe the combined oral contraceptive pill $(\mathrm{p}=0.0052)$ and the progestogen-only pill $(\mathrm{p}=0.035)$. A far greater proportion $(93 \%)$ of the Caucasian group compared to the non-Caucasian group (38\%) preferred the 'other name' (colloquial names) rather than the term 'combined oral contraceptive pill'.

\section{Information sources}

We asked the question 'What helps you to understand contraception better?'. The sources of information that the patients preferred to use to find out about contraception are shown in Table 1. Respondents were allowed to give as many sources as they wished. The most popular choice was to chat with their friends or family (123 responses), followed by information in the form of a leaflet (105). A visit to the nurse was the third most frequent response.

\section{Discussion}

This study demonstrated quite clearly that the patients in the sample preferred to use the terms they were familiar with when referring to contraception, the most popular terms being the pill, the mini-pill, the coil and the morningafter pill. A large number of women also indicated that they had no preferred term.
However, it was further demonstrated that the commonly used terms had associations that were incorrect and may be misleading. For example, almost $20 \%$ of the comments about the coil linked it to metal and springs; far fewer similar assumptions were made for the term intrauterine device. The mini-pill was often associated with something small, possibly a smaller version of the combined pill or lower dose of hormones. In comparison, the name progestogen-only pill was not associated with size. This implies that although the terms intrauterine device and progestogen-only pill were less widely recognised, when employed they conveyed accurate information to patients. It is therefore possible to suggest that contrary to what this sample of patients have indicated they prefer, a better service would be provided for them if clinic staff and other educators encouraged them to use more precise terminology.

There was a statistically significant difference in the proportions of preferred terms from the different ethnic groups. A far greater proportion of the Caucasian group preferred the common names for the combined oral contraceptive pill, e.g. the pill, when compared to the nonCaucasian group. This may be because people from ethnic groups who do not speak English as their first language may not use colloquial terms in their everyday life, and so find the precise terms easier to accept.

At present, the precise terms are perceived to some extent as medical jargon by the public, as demonstrated by the considerable number of respondents who said they did not know or understand them. Therefore to avoid alienating patients, the use of these terms must be accompanied by full explanations using simple language, perhaps using the common term at the same time to clarify that they are one and the same thing. All clinic staff should be aware of this, and both kinds of terms could be incorporated into written material.

Statements on funding and competing interests

Funding. None identified.

Competing interests. None identified.

References

1 Gull S. Communication skills: recognising the difficulties. The Obstetrician and Gynaecologist 2002; 4: 107-110.

2 Kurtz S. Curriculum structuring to enhance communication skills development. In: Stewart M, Roter D (eds), Communication with Medical Patients. Newbury Park, CA: Sage Publications, 1989.

3 Elwyn G, Gwyn R. Stories we hear and stories we tell: analysing talk in clinical practice. BMJ 1999; 38: 186-188.

4 Makoul G, Arnston P, Schofield T. Health promotion in primary care: Physician-patient communication and decision making about prescription medications. Soc Sci Med 1995; 41: 241-254.

5 Mills A, Edwards R. Venous thromboembolism and the combined oral contraceptive pill. Are poor communication systems responsible for loss of confidence in this contraceptive method? Hum Reprod 1999; 14: 7-10.

6 Davis D, Wysocki S. Clinician/patient interaction: communicating the benefits and risks of oral contraceptives. Contraception 1999; 59: 39S-42S.

7 www.plainenglish.co.uk [Accessed 14 June 2002].

8 Waitzhin H. Information giving in medical care. J Health Soc Behav 1985; 26: 81-101

9 McKinley J. Who is really ignorant: physician or patient? J Health Soc Behav 1975; 16: 3-11.

10 Heath $\mathrm{C}$. The delivery and reception of diagnosis in the generalpractice consultation. In: Drew P, Heritage J (eds), Talk at Work. Cambridge, UK: Cambridge University Press, 1993.

11 Hennick M, Cooper P, Diamond I. Asian women's use of family planning services. Br J Fam Plann 1998; 24: 43-52.

12 Ebden P, Bhatt A Carey OJ, et al. The bilingual consultation. Lance 1988; 1: 347. 